\title{
Treatment of Postoperative Lymphatic Leakage Applying Transpedal Lymphangiography - Experience in 355 Consecutive Patients
}

\section{Behandlung von postoperativen Lymphleckagen mittels transpedaler Lymphangiografie - Erfahrungsbericht bei 355 aufeinanderfolgenden Patienten}

Authors

Feng Pan ${ }^{1,2}$, Goetz M Richter ${ }^{3}$, Thuy Duong Do ${ }^{1}$, Hans-Ulrich Kauczor ${ }^{1}$, Rosa Klotz ${ }^{4}$, Thilo Hackert ${ }^{4}$, Martin Loos $^{4}$, Christof M. Sommer $1,3,5,6$ (B)

Affiliations

1 Clinic of Diagnostic and Interventional Radiology, University Hospital Heidelberg, Germany

2 Department of Radiology, Union Hospital, Tongji Medical College, Huazhong University of Science and Technology, Wuhan, China

3 Clinic for Diagnostic and Interventional Radiology, Klinikum Stuttgart Katharinenhospital, Stuttgart, Germany

4 Department of General, Visceral and Transplantation Surgery, University Hospital Heidelberg, Germany

5 Department of Nuclear Medicine, University Hospital Heidelberg, Germany

6 Clinic of Radiology and Neuroradiology, Sana Clinics Duisburg, Germany

Key words

lymphography, lymphatic, fistula, postoperative

complications, treatment effects

received 31.05.2021

accepted 18.11.2021

published online 26.01.2022

Bibliography

Fortschr Röntgenstr 2022; 194: 634-643

DOI 10.1055/a-1717-2467

ISSN 1438-9029

(c) 2022. Thieme. All rights reserved.

Georg Thieme Verlag KG, Rüdigerstraße 14,

70469 Stuttgart, Germany

Correspondence

Dr. Christof M Sommer

Clinic of Diagnostic and Interventional Radiology, University Hospital Heidelberg, INF 420, 69120 Heidelberg, Germany

Tel.: +49/6221/5661 10

cmsommer@gmx.com

Supplementary material is available under

https://doi.org/10.1055/a-1717-2467

\section{ABSTRACT}

Purpose Report of experience from a single institution in treating postoperative lymphatic leakage (PLL) applying conventional transpedal lymphangiography (TL).

Materials and Methods 453 patients with the initial diagnosis of PLL receiving TL between 03/1993 and 09/2018 were identified in the database. Only patients with confirmed PLL were included in the study. The technical success, safety, and treatment success of TL were evaluated. Independent predictors of TL treatment failure were examined using univariate and multivariate logistic regression analysis.

Results 355 consecutive patients (218 men, 137 women; median age of 62 years) who underwent TL for PLL (e. g., chylothorax) after ineffective conservative treatment were included. The median time between causal surgery and TL was 27 days. The median technical success rate of TL was $88.5 \%$, with a median volume of Lipiodol of $10.0 \mathrm{ml}$. No complication of TL was recorded. Three groups were defined according to the different clinical courses: group A $(41 / 355,11.5 \%)$ - TL with technical failure; group B (258/355, $72.7 \%)$ - "therapeutic" TL alone with technical success; and group C (56/355, $15.8 \%)$ - "diagnostic" TL with simultaneously invasive treatment (incl. surgical revision and percutaneous sclerotherapy). Treatment success rate and median time to treatment success were higher in group $C$ than in group $B$, but without significant differences ( $64.3 \%$ vs. $61.6 \%, p=0.710$; six vs. five days, $\mathrm{p}=0.065)$. Univariate and multivariate logistic regression analyses for group B confirmed drainage volume (>500 ml/d) and Lipiodol extravasation as independent predictors of TL clinical failure (odds ratios [ORs] of 2.128 and 2.372 [p = 0.005 and $\mathrm{p}=0.003$, respectively]).

Conclusion TL is technically reliable, safe, and effective in treating PLL. When conservative treatment fails, TL can be regarded as the next treatment option.

Key Points:

- TL is technically reliable, safe, and effective for treating PLL.

- When conservative treatment fails, TL can be regarded as the next treatment option. 
- Drainage volume $>500 \mathrm{ml} /$ day is an independent predictor of clinical failure after TL.

- Lipiodol extravasation is an independent predictor of clinical failure after TL.

\section{Citation Format}

- Pan F, Richter GM, Do TD et al. Treatment of Postoperative Lymphatic Leakage Applying Transpedal Lymphangiography - Experience in 355 Consecutive Patients. Fortschr Röntgenstr 2022; 194: 634-643

\section{ZUSAMMENFASSUNG}

Ziel Erfahrungsbericht über die interventionelle Behandlung der postoperativen Lymphleckage (PLL) mittels konventioneller transpedaler Lymphangiografie ( $\mathrm{TL})$.

Material und Methoden Über digitale Datenbanken konnten 453 Patienten identifiziert werden, die in unserer Klinik zwischen 03/1993 und 09/2018 eine TL erhielten. Von diesen Patienten wurden lediglich diejenigen eingeschlossen, die eine TL aufgrund einer PLL erhielten. Der technische Erfolg, die Sicherheit und das klinische Ergebnis der TL wurden bewertet. Unabhängige Prädiktoren für das klinische Versagen nach TL wurden mittels univariater und multivariater logistischer Regressionsanalyse identifiziert.

Results Bei 355 konsekutiven Patienten (218 Männer, 137 Frauen; medianes Alter 62 Jahre) wurde eine TL bei klinischem Versagen nach konservativer Behandlung einer PLL (z. B. Chylothorax) durchgeführt. Das mediane Zeitintervall zwischen kausaler Operation und TL betrug 27 Tage. Die mediane technische Erfolgsrate von TL betrug $88,5 \%$ bei einem medianen Lipiodol-Volumen von 10,0 ml. Es wurde keine Kom- plikation der TL beobachtet. Entsprechend den verschiedenen klinischen Verläufen wurden 3 Patientengruppen definiert: Gruppe A (41/355, 11,5\%) - TL mit technischem Versagen; Gruppe B (258/355, 72,7\%) - „therapeutische“ TL allein mit technischem Erfolg; und Gruppe C (56/355, 15,8\%) - „diagnostische" TL mit gleichzeitig invasiver Behandlung (inkl. chirurgische Revision und perkutane Sklerotherapie). Die mediane klinische Erfolgsrate und das mediane Zeitintervall bis zum klinischen Erfolg nach TL waren in Gruppe C höher als in Gruppe B, jedoch ergaben sich hierbei keine signifikanten Unterschiede $(64,3 \%$ vs. $61,6 \%, p=0,710 ; 6$ vs. 5 Tage, $p=0,065)$. Univariate und multivariate logistische Regressionsanalysen für Gruppe B identifizierten das Drainagevolumen (>500 ml/Tag) und die Extravasation von Lipiodol als unabhängige Prädiktoren für das klinische Versagen nach TL (Odds Ratios [ORs] von 2,128 und 2,372 [ $p=0,005$ bzw. $p=0,003$ ]). Schlussfolgerung Die TL ist technisch zuverlässig, sicher und wirksam bei der Behandlung der PLL. Wenn die konservative Behandlung versagt, kann die TL als nächste Behandlungsoption angesehen werden.

\section{Kernaussagen:}

- Die TL ist technisch zuverlässig, sicher und wirksam bei der Behandlung der PLL.

- Wenn die konservative Behandlung versagt, kann die TL als nächste Behandlungsoption angesehen werden.

- Ein Drainagevolumen von > 500 ml/Tag ist ein unabhängiger Prädiktor für klinisches Versagen nach TL.

- Die Extravasation von Lipiodol ist ein unabhängiger Prädiktor für das klinische Versagen nach TL.

\section{Introduction}

Postoperative lymphatic leakage (PLL) is a rare but potentially severe complication caused by inadvertent destruction of lymphatic vessels during different surgeries, such as malignancy resection, transplantation, and cardiovascular surgery [1]. It may cause the loss of a large amount of lymph fluid, leading to malnutrition, reduced immunity, and increased risk of infection [1-3]. Especially in patients with high-output PLL (> $1 \mathrm{~L} /$ day) without effective treatment, it can lead to life-threatening nutritional, metabolic, and immunologic sequelae with a mortality rate of up to $50 \%$ [3-9].

Conservative treatments, such as nutrition management (e. g., total parenteral nutrition with a fat-free supplement, low-fat supplement with medium-chain triglycerides, etc.), administration of somatostatin analog, sufficient drainage therapy, wound management like vacuum-assisted closure, and so on are the first-line choices, which can reach a success rate of more than $60 \%[2,3,8$, $10,11]$. However, in patients with high-output PLL, inadequate response to conservative treatment was a significant dilemma, which prolonged the treatment period (always several weeks or months), leading to tolerability problems [10]. Surgical revision (e. g., lymphatic vessel ligation, lymphocele fenestration, etc.) as an alternative treatment can cause secondary damage to the body, even fatal events $[1,3,11,12]$.

As another effective minimally invasive treatment for PLL, conventional transpedal lymphangiography (TL) has been increasingly used in clinical practice for the past decades. It is not only a "diagnostic" tool to identify the PLL site facilitating further invasive treatments, but also can "therapeutically" tackle the different types of PLLs, including cervical chylous fistula, chylothorax, chylous ascites, lymphatic lymphocele in the pelvis, and lymphocutaneous fistula in the groin/lower extremity [1, 3, 13-15]. In a recent systematic review, TL demonstrated good efficiency and safety to treat PLL with a total treatment success rate between $50 \%$ and $70 \%$ and a complication rate of less than $3 \%$ [1]. However, most of the reports have limited sample sizes with less than 20 patients [1]. So far, largescale research to explore the statistical efficiency of TL and predictors of TL treatment failure is still lacking. Our center has more than 25 years of experience in TL, which has been established as a standardized technique for treating PLL since then. The purpose of our study is to provide a monocentric report of our experience treating PLL using conventional TL. 


\section{Materials and Methods}

All procedures performed in this study involving human participants comply with the institution's ethical standards, the ethical regulations of the National Research Council, and the 1964 Declaration of Helsinki and its subsequent amendments.

\section{Study population}

In the retrospective review of the institutional digital database between 03/1993 and 09/2018, 453 patients undergoing TL were identified. Patients with confirmed PLL due to different types of surgeries and receiving the following TL were included. The diagnosis criteria of PLL included: 1. exclusion of other postoperative complications, such as malignant pleural effusion/ascites and inflammatory exudation; 2 . milky fluid leakage with the triglyceride level $>110 \mathrm{mg} / \mathrm{dl}$ or presence of chylomicron in the drained fluid; or non-milky fluid leakage with positive patent blue $\mathrm{V}$ dye test or lymphatic leakage confirmed by TL [2, 3, 16-18].

\section{TL-based treatment strategies}

TL is routinely performed in our center if PLL persisted after conservative treatments of PLL (e. g., nutrition management, somatostatin analogs, and drainage for chylous leakage; wound vacuum therapy and percutaneous drainage for non-chylous leakage) for more than 2 weeks. Two TL-based strategies were used in our center: one is "therapeutic" TL which is performed alone to treat PLL; the other is "diagnostic" TL with simultaneously invasive treatment, including surgical revision (e. g., lymphatic vessel ligation, lymphocele fenestration, etc.) or percutaneous sclerotherapy (incl., afferent lymphatic vessel sclerotherapy and direct leakage sclerotherapy), in which TL is used to delineate the lymphatic structure facilitating further treatment $[14,19]$. Both the "therapeutic" and "diagnostic" TLs have the same techniques. Severe pulmonary dysfunction identified by spirometry, pulmonary arterial-venous malformation, and cardiac right-to-left shunting are contraindications for TL.

\section{TL procedure}

Details of the TL technique have been previously described [13, $18,19]$. Informed consent was obtained at least 24 hours before treatment. 15 to 30 minutes after intradermal injection of $1-3 \mathrm{ml}$ blue dye [mixture of $4 \mathrm{ml} / 100 \mathrm{mg}$ Patent Blue V (Guerbet, Roissy, France) and $4 \mathrm{ml}$ Xylocaine $1 \%$ (lidocaine; AstraZeneca, London, United Kingdom)] into 1st-3 rd interdigital space of the foot, the dorsal lymphatic vessels can be visually identified. Then, a small incision is made on the dorsal foot, and the subcutaneous lymphatic vessels are selectively dissected under local anesthesia. A 21- to 25-G venous cannula (BD Vasculon Plus; BD, Heidelberg, Germany) is used to puncture the target lymphatic vessel and is fixed with sutures. After that, Lipiodol (Guerbet, Roissy, France) with a median volume of $10.0 \mathrm{ml}$ (IQR: $7.5-12.0 \mathrm{ml}$; range: $5.0-$ $25.0 \mathrm{ml}$ ) is manually injected through this lymphatic access under fluoroscopy with a velocity of about $0.1-0.5 \mathrm{ml} / \mathrm{min}$ for about 1 hour. To ensure that the Lipiodol propagates to different target areas, the appropriate timing of radiography is essential using the following as a reference: $0-1 \mathrm{~h}, 1-3 \mathrm{~h}$, and $4-6 \mathrm{~h}$ from initiation of the injection for lymphatic visualization at the lower extremity and groin, pelvis and abdomen, and thorax and neck, respectively $[13,14,19]$. If indeterminate Lipiodol extravasation is observed in radiography, simultaneous $\mathrm{CT}$ (filling phase) is performed due to its higher sensitivity $[14,19]$. If Lipiodol extravasation is still not marked, CT would be re-performed 24 hours later (nodal phase) for further diagnosis $[14,19]$.

The technical success of TL is defined as effective cannulation of the lymphatic vessels for the injection of Lipiodol and successful imaging of the lymphatic system in the area of interest $[1,18$, 20-22]. Lipiodol extravasation is defined as the pathological distribution of Lipiodol out of the lymphatic vessels on radiography or CT, indicating rupture of lymphatic vessels [14, 18, 23-25]. The complications of TL were recorded and retrospectively classified following the grades system from the Society of Interventional Radiology [26].

\section{Follow-up}

Treatment success was defined as a gradual reduction to the final cessation of PLL without further treatments, thereby withdrawing the drainage within two weeks after completing the therapy [18, 27-29]. The clinical outcomes of all patients were collected and summarized from the institutional electronic records.

\section{Statistical analysis}

Statistical analysis was performed using IBM SPSS Statistics Software (version 26; IBM, New York, USA). Quantitative data were presented as median with interquartile range (IQR) and the counting data as count with the percentage of the total. All tests were two-sided, with the significant difference level defined as $p<0.05$. The comparison of the quantitative data was evaluated using the Mann-Whitney $U$ test due to the non-Gaussian distribution identified by the Shapiro-Wilk test. The counting data comparison was assessed using the Chi-square test or Fisher's exact test if the expected count was less than five. Patients undergoing "therapeutic" TL with technical success were involved in exploring predictors of TL treatment failure, such as the period between the surgery and TL, the output of PLL, Lipiodol extravasation, and the volume of Lipiodol injected in TL. Univariate and multivariate logistic regression analyses were performed to determine the independent predictors of treatment failure through a stepwise forward method. The probability for variable entry was set as less than 0.10 . The odds ratio (OR) with a $95 \%$ confidence interval $(95 \% \mathrm{Cl})$ was calculated.

\section{Results}

\section{Patient characteristics}

453 patients undergoing TL were included in the study, and 98 patients were excluded due to unconfirmed suspicion PLL. Eventually, 355 patients (median age: 62 years, IQR: 51-69 years) with a male-to-female ratio of 1.6:1 were enrolled. Nearly half of the patients (165/355, 46.5\%) developed PLL after malignant tumor resection in different organs or tissues (e. g., esophagus, stomach, etc.). Among them, 159 patients underwent simultaneous 
lymphadenectomy (159/165, 96.4\%). The median period between causal surgery and TL was 27 days (IQR: 17-54 days). The median output of PLL was $500 \mathrm{ml} / \mathrm{d}$ (IQR: 300-1100 ml). The details of the enrolled patients are summarized in $>$ Table 1.

\section{Technical success of the TL}

The rate of technical success was $88.5 \%$ (314/355). In 41 patients with technically failed $\mathrm{TL}$, the main reason was the unsuccessful puncture of the lymphatic vessels $(27 / 41,65.9 \%)$, followed by the local lymphatic vessel dissection $(13 / 41,31.7 \%$ ) and accidental dislocation of the cannula $(1 / 41,2.4 \%)(\triangleright$ Table 2$)$. In patients with chylothorax, the significantly higher median volume of Lipiodol $(13.0 \mathrm{ml})$ was required in TL when compared with chylous ascites $(10.0 \mathrm{ml})$, pelvic lymphocele $(9.0 \mathrm{ml})$, lymphocutaneous fistula in the groin $(10.0 \mathrm{ml})$, and lymphocutaneous fistula in the lower extremity $(10.0 \mathrm{ml})$ ( $\mathrm{p} \leq 0.048$, each). After TL, Lipiodol extravasation was identified in $66.6 \%$ of patients (209/314) ( $\triangleright$ Table 2). No complications of TL were recorded.

\section{Summary of the clinical course}

Patients were divided into three groups according to the clinical course ( $\triangleright$ Table 3): group A (41/355, 11.5\%) - TL with technical failure; group B (258/355, 72.7\%) - "therapeutic" TL with technical success; and group C (56/355, 15.8\%) - "diagnostic" TL with simultaneously invasive treatment (incl. TL plus surgical revision or percutaneous sclerotherapy). Compared with groups A and B, the percentage of chylous ascites was significantly lower and the rate of pelvic lymphocele significantly higher in group $C$ $(p \leq 0.004)$.

In group B, treatment success of "therapeutic" TL was achieved in 159 patients $(159 / 258,61.6 \%)$ after a median of 5 days (IQR: 2-7 days) from TL ( $\triangleright$ Table 3$)$. In group C, 41 patients (41/56, $73.2 \%)$ and 15 patients $(15 / 56,26.8 \%)$ underwent the "diagnostic" TL with simultaneous surgical revision and percutaneous sclerotherapy, respectively. This resulted in treatment success in 36 patients $(36 / 56,64.3 \%)$ after a median of 6 days (IQR: $3-$ 11 days) from TL) ( $\vee$ Table 3$)$. There were no significant differences in treatment success rate $(61.6 \%$ vs. $64.3 \%, p=0.710)$ and the time from TL to treatment success (median: 5 vs. 6 days, $\mathrm{p}=0.065$ ) between groups $\mathrm{B}$ and $\mathrm{C}(\triangleright$ Table 3$)$.

In total, there are 160 patients (160/355, $45.1 \%$ ) with technical or treatment failure of TL-based therapies. For them, a variety of alternative therapies were performed, including surgical revision, percutaneous sclerotherapy, low-dose radiotherapy (total dose from 8 to $12 \mathrm{~Gy}$ ), repeated "therapeutic" TL, and continuously conservative treatment. As a result, PLL was finally resolved in 138 patients $(138 / 160,86.2 \%)$ after a median of 37 days (IQR: 24-64) from TL. 20 patients $(20 / 160,8.8 \%)$ with persistent PLL were discharged due to refusal of further treatments and 2 patients $(2 / 160,1.2 \%)$ died from PLL. The details of the clinical course were illustrated in Electronic Supplementary Material 1 to 3.

\section{Factors associated with treatment failure of "therapeutic" TL}

To explore the factors associated with TL treatment failure, patients in group B (“therapeutical” TL with technical success) were divided into two subgroups: Subgroup 1 (treatment failure, 159/ $258,61.6 \%$ ) and subgroup 2 (treatment success, 99/258, 38.4\%) ( $\triangleright$ Table 4). As a result, it showed significant differences in the output of PLL and Lipiodol extravasation between the two subgroups ( $p<0.001$ and $=0.014$, respectively) ( $\triangleright$ Table 4$)$. The univariate logistic regression analysis revealed that two factors, including the output of PLL $>500 \mathrm{ml} / \mathrm{d}$ and Lipiodol extravasation, were significantly correlated with treatment failure of $\mathrm{TL}$ $(p=0.025$ and 0.014 , respectively) ( $\triangleright$ Table 5). Further multivariate logistic regression analysis showed an optimal fitting involving these two factors, with ORs of 2.128 and 2.372 , respectively $(p=0.005$ and 0.003 , respectively) ( $\triangleright$ Table 5$)$.

\section{Discussion}

Our study analyzed the data of 355 patients who underwent TL treatment for different types of PLLs (e. g., cervical chylous fistula, chylothorax, etc.) in this institution within 25 years. Nearly half of the patients underwent malignant tumor resection preceding PLL occurrence, with more than $95 \%$ of patients undergoing lymphadenectomy. In patients with technically successful TL (314/355, $88.5 \%$ ), Lipiodol extravasation was observed in two-thirds of patients (209/314, 66.6\%). No complication of TL was recorded. Two TL-based strategies were performed in our cohort: "therapeutic" TL and "diagnostic" TL with simultaneously invasive treatment, achieving a treatment success rate of $61.6 \%(159 / 258)$ and 64.3 \% (36/56), respectively. An output of PLL > $500 \mathrm{ml} / \mathrm{d}$ and $\mathrm{Li}-$ piodol extravasation in TL are independent predictors of TL treatment failure, with ORs of 2.128 and 2.372, respectively ( $p=0.005$ and 0.003 , respectively).

Lipiodol applied in TL can seal small lymphatic leakage and induce local sterile inflammation benefiting histological revision $[1,3,13]$. However, as a liquid embolized agent, Lipiodol can cause ectopic embolism leading to fatal events [30, 31]. Although regular pulmonary capillary beds can block viscous Lipiodol preventing any clinically relevant pulmonary or systemic embolism, some contraindications should be noted, including severe pulmonary dysfunction, pulmonary arterial-venous malformation, and right-to-left shunting in the heart $[28,30,31]$, because under these conditions, normal pulmonary capillary filtration can be destroyed [30, 31]. Thus, interventional radiologists need to understand the risks of this procedure and perform preoperative assessments meticulously.

According to previous literature, TL's reported technical success rate is over $90 \%$, similar to the rate of $88.5 \%$ (314/355) seen in our study [1]. Most TL failures are ascribed to the too-small diameter of the lymphatic vessels in the feet, resulting in puncture failure or dissection. Thus, the decisive factor for technical success mainly depends on the anatomy of the pedal lymphatic vessels. In the past decade, an alternative to TL named "intranodal lymphangiography (IL)" has become increasingly more common in the treatment of PLL. IL is less technically challenging and less invasive than TL but with a comparable technical success rate and treatment efficiency [1, 32-36]. However, IL still has some drawbacks. Firstly, due to no suture fixation of the cannula like TL, leakage of Lipiodol into the surrounding tissue space can be observed, 
- Table 1 Patient characteristics.

Tab. 1 Patientencharakteristik.

\begin{tabular}{|c|c|}
\hline & Results \\
\hline Age (years) (IQR) & $62(51-69)$ \\
\hline \multicolumn{2}{|l|}{ Sex } \\
\hline Male & $218 / 355(61.4 \%)$ \\
\hline Female & $137 / 355(38.6 \%)$ \\
\hline \multicolumn{2}{|l|}{ Initial diagnosis } \\
\hline Terminal renal insufficiency & $74 / 355$ (20.8\%) \\
\hline Abdominal carcimoma/sarcoma (e. g., gastric carcinoma, liposarcoma, etc.) & $59 / 355(16.6 \%)$ \\
\hline Peripheral artery disease & $36 / 355(10.1 \%)$ \\
\hline Malignant melanoma (incl. groin and lower extremity) & $23 / 355(6.5 \%)$ \\
\hline Aortic aneurysm/dissection & $21 / 355(5.9 \%)$ \\
\hline Pelvic carcimoma/sarcoma (e. g. cervical carcinoma, liposarcoma, etc.) & $19 / 355(5.4 \%)$ \\
\hline Vulvar squamous cell carcinoma & $17 / 355(4.8 \%)$ \\
\hline Esophagus carcinoma & $16 / 355(4.5 \%)$ \\
\hline Coronary heart disease & $12 / 355(3.4 \%)$ \\
\hline Valvular heart disease & $7 / 355(2.0 \%)$ \\
\hline Other benign diseases (e. g., femoral hernia, cholangitis, etc.) & $40 / 355(11.3 \%)$ \\
\hline Other malignant tumors (e. g., subcutaneous liposarcoma, lymphoma, etc.) & $31 / 355(8.7 \%)$ \\
\hline \multicolumn{2}{|l|}{ Causal surgery } \\
\hline Explorative laparotomy with tumor resection & $95 / 355(26.8 \%)$ \\
\hline Kidney transplantation & $67 / 355(18.9 \%)$ \\
\hline Transfemoral catheterization (e. g., cardiopulmonary bypass, EVAR) & $53 / 355(14.9 \%)$ \\
\hline Cutaneous/subcutaneous tumor resection (incl. groin and lower extremity) & $53 / 355(14.9 \%)$ \\
\hline Peripheral artery bypass & $24 / 355(6.8 \%)$ \\
\hline Thoracic-abdominal esophagus resection & $19 / 355(5.4 \%)$ \\
\hline Vulvectomy & $14 / 355(3.9 \%)$ \\
\hline Subcutaneous hematomectomy with vascular repair & $9 / 355$ (2.5\%) \\
\hline Explorative thoracotomy & $3 / 355(0.8 \%)$ \\
\hline Radical thyroid tumor resection & $3 / 355(0.8 \%)$ \\
\hline Artificial femoral head replacement & $3 / 355(0.8 \%)$ \\
\hline Others (e. g., liver transplantation, hernia repair) & $12 / 355(3.4 \%)$ \\
\hline Lymphadenectomy in surgery & $159 / 355(44.8 \%)$ \\
\hline \multicolumn{2}{|l|}{ Clinical diagnosis of PLL } \\
\hline Cervical chylous fistula & $4 / 355(1.1 \%)$ \\
\hline Chylothorax & $35 / 355(9.9 \%)$ \\
\hline Chylous ascites & $64 / 355(18.0 \%)$ \\
\hline Chyloretroperitonum & $8 / 355(2.3 \%)$ \\
\hline Pelvic lymphocele & $88 / 355(24.8 \%)$ \\
\hline Lymphocutaneous fistula in groin & $134 / 355(37.7 \%)$ \\
\hline Lymphocutaneous fistula in lower extremity & $22 / 355(6.2 \%)$ \\
\hline Output of PLL (ml/d) (IQR) & $500(300-1100)$ \\
\hline Cervical chylous fistula & $1100(450-2850)$ \\
\hline Chylothorax & $1200(700-2100)$ \\
\hline
\end{tabular}


- Table 1 (Continuation)

\begin{tabular}{|l|l|}
\hline & Results \\
\hline Chylous ascites & $1250(825-3000)$ \\
\hline Chyloretroperitonum & $738(300-2100)$ \\
\hline Pelvic lymphocele & $600(400-925)$ \\
\hline Lymphocutaneous fistula in groin & $300(200-400)$ \\
\hline Lymphocutaneous fistula in lower extremity & $300(250-500)$ \\
\hline Period between causal surgery and TL (d) (IQR) & $27(17-54)$ \\
\hline \begin{tabular}{l} 
EVAR: endovascular aortic repair; IQR: interquartile range; PLL: postoperative lymphatic leakage; TL: transpedal lymphangiography. \\
\hline
\end{tabular}
\end{tabular}

- Table 2 Technical details of the TL.

- Tab. 2 Technische Details der TL.

\begin{tabular}{|c|c|}
\hline & Results \\
\hline \multicolumn{2}{|l|}{ Site of puncture } \\
\hline Left foot & $165 / 355(46.5 \%)$ \\
\hline Right foot & $150 / 355(42.3 \%)$ \\
\hline Both feet & $40 / 355(11.3 \%)$ \\
\hline Technical success & $314 / 355(88.5 \%)$ \\
\hline Volume of Lipiodol injected in TL (ml) (IQR) ${ }^{1}$ & $10.0(7.5-12.0)$ \\
\hline Cervical chylous fistula (IQR) & $10.0(9.0-11.0)$ \\
\hline Chylothorax (IQR) & $13.0(8.0-16.5)^{2}$ \\
\hline Chylous ascites (IQR) & $10.0(7.5-12.5)$ \\
\hline Chyloretroperitonum (IQR) & $10.0(5.5-12.5)$ \\
\hline Pelvic lymphocele (IQR) & $9.0(7.0-10.0)$ \\
\hline Lymphocutaneous fistula in groin (IQR) & $10.0(8.0-13.0)$ \\
\hline Lymphocutaneous fistula in lower extremity (IQR) & $10.0(8.0-10.5)$ \\
\hline Lipiodol extravasation² & 209/314 (66.6\%) \\
\hline Technical failure & $41 / 355(11.5 \%)$ \\
\hline Unsuccessful puncture & $27 / 41(65.9 \%)$ \\
\hline Local lymphatic vessel dissection after a successful puncture & $13 / 41(31.7 \%)$ \\
\hline Accidental dislocation of the cannula & $1 / 41(2.4 \%)$ \\
\hline \multicolumn{2}{|c|}{$\begin{array}{l}\text { IQR: interquartile range; PLL: postoperative lymphatic leakage; TL: transpedal lymphangiography. } \\
\text { IQR, Interquartilsabstand; PLL, postoperative Lymphleckage; TL, transpedale Lymphangiografie. } \\
1 \text { Only patients with technically successful TL were analyzed. } \\
\text { Ausgewertet wurden nur Patienten mit technisch erfolgreicher TL. } \\
2 \text { Using Mann-Whitney tests, it showed a significantly higher Lipiodol volume that was injected in TL for chylothorax when compared with chylous ascites } \\
\text { ( }(p=0.023) \text {, pelvic lymphocele }(p<0.001) \text {, Iymphocutaneous fistula in the groin }(p=0.007) \text {, and lymphocutaneous fistula in the lower extremity }(p=0.048) \text {. } \\
\text { Unter Verwendung des Mann-Whitney-Tests zeigte sich, dass bei der TL bei Chylothorax ein signifikant höheres Lipiodol-Volumen injiziert wurde, verglichen } \\
\text { mit chylösem Aszites ( }(p=0,023) \text {, pelviner Lymphozele ( }<<0,001) \text {, lymphokutaner Fistel in der Leiste }(p=0,007) \text { sowie lymphokutaner Fistel in der unteren } \\
\text { Extremität }(p=0,048) \text {. }\end{array}$} \\
\hline
\end{tabular}


- Table 3 Summary of the clinical course.

- Tab.3 Zusammenfassung des klinischen Verlaufs.

\begin{tabular}{|c|c|c|c|}
\hline & Group A $(n=41)$ & Group B $(n=258)$ & Group C ( $n=56)$ \\
\hline Age (years) (IQR) & $64(50-71)$ & $62(51-68)$ & $61(47-71)$ \\
\hline \multicolumn{4}{|l|}{ Clinical diagnosis of PLL } \\
\hline Cervical chylous fistula & $0 / 41(0.0 \%)$ & $4 / 258(1.6 \%)$ & $0 / 56(0.0 \%)$ \\
\hline Chylothorax & $3 / 41(7.3 \%)$ & $26 / 258(10.1 \%)$ & $6 / 56(10.7 \%)$ \\
\hline Chylous ascites & $8 / 41(19.5 \%)$ & $55 / 258(21.3 \%)$ & $1 / 56(1.8 \%)^{1}$ \\
\hline Chyloretroperitonum & $0 / 41(0.0 \%)$ & $7 / 258(2.7 \%)$ & $1 / 56(1.8 \%)$ \\
\hline Pelvic lymphocele & $8 / 41(19.5 \%)$ & $53 / 258(20.5 \%)$ & $27 / 56(48.2 \%)^{2}$ \\
\hline Lymphocutaneous fistula in groin & $20 / 41(48.8 \%)^{3}$ & $98 / 258(38.0 \%)$ & $16 / 56(28.6 \%)$ \\
\hline Lymphocutaneous fistula in lower extremity & $2 / 41(4.9 \%)$ & $15 / 258(5.8 \%)$ & $5 / 56(8.9 \%)$ \\
\hline Output of PLL (ml/d) (IQR) & $350(300-975)$ & $500(300-1100)$ & $625(500-1100)$ \\
\hline Period between causal surgery and TL (d) (IQR) & $24(18-40)$ & $26(16-49)$ & $36(21-57)$ \\
\hline Volume of Lipiodol injected in TL (ml) (IQR) & & $10.0(7.0-14.0)$ & $10.0(8.0-10.0)$ \\
\hline Lipiodol extravasation & & 169/258 (65.5\%) & $40 / 56(71.4 \%)$ \\
\hline $\begin{array}{l}\text { Treatment success of "therapeutic" TL/“diagnostic" TL } \\
\text { with simultaneously invasive treatment }\end{array}$ & & 159/258 (61.6\%) & $36 / 56(64.3 \%)$ \\
\hline $\begin{array}{l}\text { Time from TL to treatment success of "therapeutic" } \\
\text { TL/“diagnostic" TL with simultaneously invasive } \\
\text { treatment (d) (IQR) }\end{array}$ & & $5(2-7)^{4}$ & $6(3-11)^{4}$ \\
\hline $\begin{array}{l}\text { IQR: interquartile range; PLL: postoperative lymphatic leal } \\
\text { IQR, Interquartilsabstand; PLL, postoperative Lymphleckac } \\
1 \text { There are significant differences compared with the oth } \\
\text { Es gibt signifikante Unterschiede im Vergleich zu den an } \\
2 \text { There are significant differences compared with the oth } \\
\text { Es gibt signifikante Unterschiede im Vergleich zu den ar } \\
3 \text { There is a significant difference compared with group C } \\
\text { Es gibt einen signifikanten Unterschied im Vergleich zu } \\
4 \text { There is no significant difference compared with patien } \\
\text { Es gibt keinen signifikanten Unterschied im Vergleich zL }\end{array}$ & $\begin{array}{l}\text { : transpedal lympha } \\
\text { ranspedale Lympha } \\
\text { groups using Fisher' } \\
\text { beiden Gruppen unt } \\
\text { groups using the Ch } \\
\text { beiden Gruppen unt } \\
\text { he Chi-square test ( } \\
\text { C unter Verwendun } \\
\text { een group B and C }\end{array}$ & $\begin{array}{l}\text { y. } \\
t(p \leq 0.004) \text {. } \\
\text { dung des exakten Fis } \\
\text { st }(p<0.001) \text {. } \\
\text { dung des Chi-Quadra } \\
\text { Quadrat-Tests ( } p=0 \text {. }\end{array}$ & $\begin{array}{l}0,004) \\
0,001)\end{array}$ \\
\hline
\end{tabular}

leading to more Lipiodol consumption and discomfort [1, 13, 37]. Secondly, puncturable lymph nodes cannot be detected occasionally, resulting in the technical failure of IL [38]. Thirdly, the incidental existence of lymphaticovenous anastomoses in lymph nodes might cause pulmonary embolism in IL [37]. Finally, IL is not appropriate for patients with PLL at the groin or lower extremities, while TL is the only option in this case. In our study, PLL in the groin and lower extremities was seen in more than $40 \%$ of cases. Therefore, $T L$ is still irreplaceable.

TL's treatment success rate for different PLLs was mainly reported to be between $50 \%$ and $70 \%$ [1]. Nevertheless, the small sample size, lack of comparison, and retrospective study design were the general issues in previous studies [1]. Although our research has similar issues, it has the largest sample size to date. As a result, by using "therapeutic" TL to treat PLL, a success rate of $61.6 \%$ (159/258) was shown. In addition, our study also showed no significant difference in the success rate of TL treatment between different PLLs (e. g., $57.7 \%$ in chylothorax and $74.5 \%$ in chylous ascites) ( $p=0.102)$, which has not been reported before. Besides, the intraoperative lymphadenectomy had no significant effect on the TL treatment.

"Diagnostic" TL with simultaneously invasive treatment as another strategy was also discussed in our study, including TL plus surgical revision and percutaneous sclerotherapy. Similar to previous studies, our study showed good efficiency of this combination but did not bring any statistical benefits compared to "therapeutic" TL treatment (treatment success rate: $64.3 \%$ vs. $61.6 \%, p=0.710$; median time to treatment success: 6 vs. 5 days, $p=0.065$ ) [39-43]. There are differences in PLL types between patients with "therapeutic" TL and with "diagnostic" TL with simultaneously invasive treatment. For instance, significantly more patients underwent "diagnostic" TL with simultaneous fenestration surgery to avoid lymphocele recurrence ( $48.2 \%$ vs. $20.5 \%, p<0.001)$. So, the benefit from this combination strategy is still questionable. 
- Table 4 Comparisons between patients with and without treatment success by "therapeutic" TL.

- Tab.4 Vergleiche zwischen den Patienten mit und ohne klinischen Erfolg nach "therapeutischer" TL.

\begin{tabular}{|c|c|c|c|}
\hline & $\begin{array}{l}\text { Subgroup-1 } \\
\text { Treatment failure } \\
(n=99)\end{array}$ & $\begin{array}{l}\text { Subgroup- } 2 \\
\text { Treatment success } \\
(n=159)\end{array}$ & p-value \\
\hline Age (y) (IQR) & $62(52-68)$ & $61(51-69)$ & 0.650 \\
\hline \multicolumn{4}{|l|}{ Sex } \\
\hline Male & $59 / 99(59.6 \%)$ & $101 / 159(63.5 \%)$ & \multirow[t]{2}{*}{0.632} \\
\hline Female & 40/99 (40.4\%) & 58/159 (36.5\%) & \\
\hline Lymphadenectomy in surgery & $49 / 99(49.5 \%)$ & $75 / 159(47.2 \%)$ & 0.364 \\
\hline \multicolumn{4}{|l|}{ Clinical diagnosis of PLL } \\
\hline Cervical chylous fistula $(n=4)$ & $0 / 4(0.0 \%)$ & $4 / 4(100.0 \%)$ & \multirow[t]{7}{*}{0.102} \\
\hline Chylothorax $(n=26)$ & $11 / 26(42.3 \%)$ & $15 / 26(57.7 \%)$ & \\
\hline Chylous ascites $(n=55)$ & $14 / 55(25.5 \%)$ & $41 / 55(74.5 \%)$ & \\
\hline Chyloretroperitonum ( $n=7$ ) & $3 / 7(42.9 \%)$ & $4 / 7(57.1 \%)$ & \\
\hline Pelvic lymphocele $(n=53)$ & $26 / 53(49.1 \%)$ & $27 / 53(50.9 \%)$ & \\
\hline Lymphocutaneous fistula in groin $(n=98)$ & $37 / 98(37.8 \%)$ & $61 / 98(62.2 \%)$ & \\
\hline Lymphocutaneous fistula in lower extremity $(\mathrm{n}=15)$ & $8 / 15(53.3 \%)$ & $7 / 15(46.7 \%)$ & \\
\hline Output of PLL (ml/d) (IQR) & $600(350-1300)$ & $300(200-1100)$ & $<0.001$ \\
\hline$\leq 500 \mathrm{ml} / \mathrm{d}$ & $43 / 99(43.4 \%)$ & $92 / 159(57.9 \%)$ & \multirow[t]{2}{*}{0.024} \\
\hline$>500 \mathrm{ml} / \mathrm{d}$ & $56 / 99(56.6 \%)$ & $67 / 159(42.1 \%)$ & \\
\hline Period between surgery and TL (d) (IQR) & $28(15-63)$ & $26(16-47)$ & 0.744 \\
\hline$\leq 27$ days & $49 / 99(49.5 \%)$ & $86 / 159$ (54.1\%) & \multirow[t]{2}{*}{0.473} \\
\hline$>27$ days & $50 / 99(50.5 \%)$ & $73 / 159(45.9 \%)$ & \\
\hline Volume of Lipiodol injected in TL (ml) (IQR) & $10.0(7.0-12.0)$ & $10.0(7.5-15.0)$ & 0.073 \\
\hline$\leq 10.0 \mathrm{ml}$ & $63 / 99(63.6 \%)$ & $96 / 159(60.4 \%)$ & \multirow[t]{2}{*}{0.601} \\
\hline$>10.0 \mathrm{ml}$ & $36 / 99(36.4 \%)$ & $63 / 159(39.6 \%)$ & \\
\hline Lipiodol extravasation & $74 / 99(74.7 \%)$ & $95 / 159$ (59.7\%) & 0.014 \\
\hline
\end{tabular}

Similar to previous studies, our study confirmed an output of PLL $>500 \mathrm{ml} / \mathrm{d}$ and Lipiodol extravasation as independent predictors of TL treatment failure [1, 24, 44]. It is speculated that the extent of lymphatic rupture is positively correlated with the PLL output and Lipiodol extravasation, which will reduce the efficiency of TL treatment. Our study also provided detailed information on further treatments and outcomes for patients who experienced technical or treatment failure of TL-based therapies (160/355, $45.1 \%$ ). Five types of bailout treatment were summarized: prolonged conservative treatment, surgical revision, percutaneous sclerotherapy, low-dose radiotherapy, and repeated TL. However, each bailout treatment cannot guarantee a cure for PLL. Thus, comprehensive treatments are always required. Ultimately, PLL was resolved in most patients $(138 / 160,86.2 \%)$ but with an extended treatment period of more than five weeks.

Our study shows certain limitations. First, it lacks a comparison between "therapeutic" TL and other treatments such as surgical revision because of the institutional predominance of TL treatment for PLL. However, the treatment success rate of "therapeutic" TL is more than $60 \%$, with excellent safety. Second, our study retrospectively analyzed the data spanning an extended period. It displayed a sort of complexity of the data, including different types of causal surgeries and management for PLL in the whole clinical course, making it impossible to compare different bailout treatments statistically. 
- Table 5 Univariate and multivariate logistic regression analysis.

- Tab.5 Univariate und multivariate logistische Regressionsanalyse.

\begin{tabular}{|c|c|c|c|c|}
\hline & \multicolumn{2}{|l|}{ Univariate } & \multicolumn{2}{|l|}{ Multivariate* } \\
\hline & OR (95\% Cl) & p-value & OR (95\%Cl) & p-value \\
\hline Lymphadenectomy in surgery & $1.098(0.664-1.814)$ & 0.716 & & \\
\hline Output of PLL > $500 \mathrm{ml} / \mathrm{d}$ & $1.788(1.077-2.969)^{*}$ & 0.025 & $2.128(1.250-3.621)^{*}$ & 0.005 \\
\hline Period between surgery and TL $>27$ days & $1.202(0.727-1.987)$ & 0.473 & & \\
\hline Volume of Lipiodol injected in $\mathrm{TL} \leq 10.0 \mathrm{ml}$ & $1.148(0.684-1.928)$ & 0.601 & & \\
\hline Lipiodol extravasation & $1.994(1.147-3.467)^{*}$ & 0.014 & $2.372(1.330-4.228)^{*}$ & 0.003 \\
\hline \multicolumn{5}{|c|}{$\begin{array}{l}\text { PLL: postoperative lymphatic leakage; OR: odds ratio; } 95 \% \mathrm{Cl} \text { : } 95 \% \text { confidence period; TL: transpedal lymphangiography. } \\
\text { PLL, postoperative Lymphleckage; OR, Odds Ratio; } 95 \% \mathrm{Cl}, 95 \% \text { Konfidenzintervall; TL, transpedale Lymphangiografie. } \\
\text { Omnibus test was performed, which showed statistical significance of the model ( }<<0.001) \text {. } \\
\text { Es wurde der Omnibus-Test durchgeführt, der eine statistische Signifikanz des Modells zeigte ( }<<0,001) \text {. }\end{array}$} \\
\hline
\end{tabular}

\section{Conclusion}

As a diagnostic and therapeutic approach for PLL, TL shows a high technical success rate and good therapeutic effect on different PLLs with minimal invasion, excellent safety, and tolerability. Although there is currently no study comparing TL with other treatments, our study suggests TL can be the next treatment option for PLL if conservative treatment fails.

\section{CLINICAL RELEVANCE}

- PLL can occur after various surgical procedures and prolong the treatment period.

- TL is technically reliable, safe, and effective in treating PLL.

- TL should be regarded as a treatment option when conservative treatment fails.

- A drainage volume $>500 \mathrm{ml} /$ day is an independent predictor of clinical failure after TL.

- Lipiodol extravasation is an independent predictor of clinical failure after TL.

\section{Conflict of Interest}

Christof M Sommer: Honorary and research grant from Guerbet.

\section{References}

[1] Sommer CM, Pieper CC, Itkin M et al. Conventional Lymphangiography (CL) in the Management of Postoperative Lymphatic Leakage (PLL): A Systematic Review. Rofo 2020; 192: 1025-1035. doi:10.1055/a-11317889

[2] Sriram K, Meguid RA, Meguid MM. Nutritional support in adults with chyle leaks. Nutrition 2016; 32: 281-286. doi:10.1016/j.nut.2015.08.002
[3] Lv S, Wang Q, Zhao W et al. A review of the postoperative lymphatic leakage. Oncotarget 2017; 8: 69062-69075. doi:10.18632| oncotarget.17297

[4] Itkin M, Kucharczuk JC, Kwak A et al. Nonoperative thoracic duct embolization for traumatic thoracic duct leak: experience in 109 patients. J Thorac Cardiovasc Surg 2010; 139: 584-589; discussion 589-590 doi:10.1016/j.jtcvs.2009.11.025

[5] Nadolski G], Chauhan NR, Itkin M. Lymphangiography and Lymphatic Embolization for the Treatment of Refractory Chylous Ascites. Cardiovasc Intervent Radiol 2018; 41: 415-423. doi:10.1007/s00270-0171856-1

[6] Cope C, Kaiser LR. Management of unremitting chylothorax by percutaneous embolization and blockage of retroperitoneal lymphatic vessels in 42 patients. J Vasc Interv Radiol 2002; 13: 1139-1148. doi:10.1016/ s1051-0443(07)61956-3

[7] Baek Y, Won JH, Kong TW et al. Lymphatic Leak Occurring After Surgical Lymph Node Dissection: A Preliminary Study Assessing the Feasibility and Outcome of Lymphatic Embolization. Cardiovasc Intervent Radiol 2016; 39: 1728-1735. doi:10.1007/s00270-016-1435-x

[8] Meyer CD, McLeod IK, Gallagher DJ. Conservative Management of an Intraoperative Chyle Leak: A Case Report and Literature Review. Mil Med 2016; 181: e1180-e1184. doi:10.7205/MILMED-D-15-00240

[9] Kumar S, Kumar A, Pawar DK. Thoracoscopic management of thoracic duct injury: Is there a place for conservatism? J Postgrad Med 2004; 50: 57-59

[10] Kim BS, Kwon TG. Chylous ascites in laparoscopic renal surgery: Where do we stand? World Journal of Clinical Urology 2016; 5: 37. doi:10.5410/ wjcu.v5.i1.37

[11] Delaney SW, Shi H, Shokrani A et al. Management of Chyle Leak after Head and Neck Surgery: Review of Current Treatment Strategies. Int ] Otolaryngol 2017; 2017: 8362874. doi:10.1155/2017/8362874

[12] Schild HH, Strassburg CP, Welz A et al. Treatment options in patients with chylothorax. Dtsch Arztebl Int 2013; 110: 819-826. doi:10.3238/ arztebl.2013.0819

[13] Pieper CC, Hur S, Sommer CM et al. Back to the Future: Lipiodol in Lymphography-From Diagnostics to Theranostics. Invest Radiol 2019; 54: 600-615. doi:10.1097/RLI.0000000000000578

[14] Pan F, Loos M, Do TD et al. The roles of iodized oil-based lymphangiography and post-lymphangiographic computed tomography for specific lymphatic intervention planning in patients with postoperative lympha- 
tic fistula: a literature review and case series. CVIR Endovasc 2020; 3: 79. doi:10.1186/s42155-020-00146-x

[15] Sommer CM, Pieper CC, Offensperger F et al. Radiological management of postoperative lymphorrhea. Langenbecks Arch Surg 2021; 406: 945969. doi:10.1007/s00423-021-02094-z

[16] Xu KF, Hu XW, Tian XL et al. Clinical analysis of 123 cases of chylous effusion. Zhonghua Yi Xue Za Zhi 2011; 91: 464-468. doi:10.3760/ cma.j.issn.0376-2491.2011.07.010

[17] Liu DY, Shao Y, Shi JX. Unilateral pedal lymphangiography with noncontrast computerized tomography is valuable in the location and treatment decision of idiopathic chylothorax. J Cardiothorac Surg 2014; 9: 8. doi:10.1186/1749-8090-9-8

[18] Pan F, Loos M, Do TD et al. Percutaneous afferent lymphatic vessel sclerotherapy for postoperative lymphatic leakage after previous ineffective therapeutic transpedal lymphangiography. Eur Radiol Exp 2020; 4: 60. doi:10.1186/s41747-020-00188-9

[19] Kortes N, Radeleff B, Sommer CM et al. Therapeutic lymphangiography and CT-guided sclerotherapy for the treatment of refractory lymphatic leakage. J Vasc Interv Radiol 2014; 25: 127-132. doi:10.1016/ j.jvir.2013.10.011

[20] Hill H, Srinivasa RN, Gemmete J] et al. Endolymphatic Ethiodized Oil Intranodal Lymphangiography and Cyanoacrylate Glue Embolization for the Treatment of Postoperative Lymphatic Leak After Robot-Assisted Laparoscopic Pelvic Resection. J Endourol Case Rep 2018; 4: 66-71. doi:10.1089/cren.2018.0026

[21] Majdalany BS, Saad WA, Chick JFB et al. Pediatric lymphangiography, thoracic duct embolization and thoracic duct disruption: a single-institution experience in 11 children with chylothorax. Pediatr Radiol 2018; 48: 235-240. doi:10.1007/s00247-017-3988-5

[22] Majdalany BS, Khayat M, Downing T et al. Lymphatic interventions for isolated, iatrogenic chylous ascites: A multi-institution experience. Eur J Radiol 2018; 109: 41-47. doi:10.1016/j.ejrad.2018.10.019

[23] Kos S, Haueisen H, Lachmund U et al. Lymphangiography: forgotten tool or rising star in the diagnosis and therapy of postoperative lymphatic vessel leakage. Cardiovasc Intervent Radiol 2007; 30: 968-973. doi:10.1007/s00270-007-9026-5

[24] Kawasaki R, Sugimoto K, Fujii M et al. Therapeutic effectiveness of diagnostic lymphangiography for refractory postoperative chylothorax and chylous ascites: correlation with radiologic findings and preceding medical treatment. Am J Roentgenol 2013; 201: 659-666. doi:10.2214/Am J Roentgenol.12.10008

[25] Boffa DJ, Sands M], Rice TW et al. A critical evaluation of a percutaneous diagnostic and treatment strategy for chylothorax after thoracic surgery. Eur J Cardiothorac Surg 2008; 33: 435-439. doi:10.1016/ j.ejcts.2007.11.028

[26] Khalilzadeh O, Baerlocher MO, Shyn PB et al. Proposal of a New Adverse Event Classification by the Society of Interventional Radiology Standards of Practice Committee. J Vasc Interv Radiol 2017; 28: 1432-1437 e1433. doi:10.1016/j.jvir.2017.06.019

[27] Yoshimatsu R, Yamagami T, Miura H et al. Prediction of therapeutic effectiveness according to CT findings after therapeutic lymphangiography for lymphatic leakage. Jpn J Radiol 2013; 31: 797-802. doi:10.1007/s11604-013-0252-2

[28] Gruber-Rouh T, Naguib NNN, Lehnert T et al. Direct lymphangiography as treatment option of lymphatic leakage: indications, outcomes and role in patient's management. Eur J Radiol 2014; 83: 2167-2171. doi:10.1016/j.ejrad.2014.09.013
[29] Kim SW, Hur S, Kim SY et al. The Efficacy of Lymph Node Embolization Using N-Butyl Cyanoacrylate Compared to Ethanol Sclerotherapy in the Management of Symptomatic Lymphorrhea after Pelvic Surgery. J Vasc Interv Radiol 2019; 30: 195-202 e191. doi:10.1016/j.jvir.2018.09.038

[30] Sheybani A, Gaba RC, Minocha J. Cerebral Embolization of Ethiodized Oil following Intranodal Lymphangiography. Semin Intervent Radiol 2015; 32: 10-13. doi:10.1055/s-0034-1396957

[31] Geeroms B, Demaerel P, Wauters ] et al. Devastating cerebral Lipiodol(R) embolization related to therapeutic lymphangiography for refractory chylothorax in a patient with Behcet's disease. Vasa 2018; 47: 427-430. doi:10.1024/0301-1526/a000715

[32] Nadolski G], Itkin M. Feasibility of ultrasound-guided intranodal lymphangiogram for thoracic duct embolization. J Vasc Interv Radiol 2012; 23: 613-616. doi:10.1016/j.jvir.2012.01.078

[33] Williams AM, Seay TM, Hundley JC et al. Direct intranodal lymphangiography for recurrent chylous ascites following liver-kidney transplantation. Liver Transpl 2014; 20: 1275-1276. doi:10.1002/It.23939

[34] Kariya S, Nakatani M, Yoshida R et al. Repeated Intranodal Lymphangiography for the Treatment of Lymphatic Leakage. Lymphology 2015; 48: 59-63

[35] Parvinian A, Mohan GC, Gaba RC et al. Ultrasound-guided intranodal lymphangiography followed by thoracic duct embolization for treatment of postoperative bilateral chylothorax. Head Neck 2014; 36: E21E24. doi:10.1002/hed.23425

[36] Kozlov A, Itkin M, Dori Y et al. Comparison of pedal and intranodal lymphangiography for thoracic duct embolization (TDE) of traumatic chylous leaks. Journal of Vascular and Interventional Radiology 2017; 28: S135. doi:10.1016/j.jvir.2016.12.924

[37] Kariya S, Komemushi A, Nakatani M et al. Intranodal lymphangiogram: technical aspects and findings. Cardiovasc Intervent Radiol 2014; 37 : 1606-1610. doi:10.1007/s00270-014-0888-z

[38] Iwai T, Uchida J, Matsuoka Y et al. Experience of Lymphangiography as a Therapeutic Tool for Lymphatic Leakage After Kidney Transplantation. Transplant Proc 2018; 50: 2526-2530. doi:10.1016/ j.transproceed.2018.03.095

[39] Smolock AR, Nadolski G, Itkin M. Intranodal Glue Embolization for the Management of Postsurgical Groin Lymphocele and Lymphorrhea. J Vasc Interv Radiol 2018; 29: 1462-1465. doi:10.1016/j.jvir.2018.04.020

[40] Srinivasa RN, Chick JFB, Patel N et al. Transinguinal interstitial (intranodal) lymphatic embolization to treat high-output postoperative lymphocele. J Vasc Surg Venous Lymphat Disord 2018; 6: 373-375. doi:10.1016/j.jvsv.2018.01.005

[41] Nadolski G], Itkin M. Lymphangiography and thoracic duct embolization following unsuccessful thoracic duct ligation: Imaging findings and outcomes. J Thorac Cardiovasc Surg 2018; 156: 838-843. doi:10.1016/ j.jtcvs.2018.02.109

[42] Chu HH, Shin JH, Kim JW et al. Lymphangiography and Lymphatic Embolization for the Management of Pelvic Lymphocele After Radical Prostatectomy in Prostatic Cancer. Cardiovasc Intervent Radiol 2019; 42: 873-879. doi:10.1007/s00270-019-02209-6

[43] Yannes M, Shin D, McCluskey K et al. Comparative Analysis of Intranoda Lymphangiography with Percutaneous Intervention for Postsurgical Chylous Effusions. J Vasc Interv Radiol 2017; 28: 704-711. doi:10.1016/ j.jvir.2016.12.1209

[44] Alejandre-Lafont E, Krompiec C, Rau WS et al. Effectiveness of therapeutic lymphography on lymphatic leakage. Acta Radiol 2011; 52: 305311. doi:10.1258/ar.2010.090356 